\title{
The Impact of a Telephone-Based Chronic Disease Management Program on Medical Expenditures
}

\author{
George Avery, PhD, MPA, David Cook, MD, MPH, and Sheila Talens, BA, BSN, RN ${ }^{1}$
}

\begin{abstract}
The impact of a payer-provided telephone-based chronic disease management program on medical expenditures was evaluated using claims data from 126,245 members in employer self-ensured health plans (16,224 with a chronic disease in a group enrolled in the self-management program, 13,509 with a chronic disease in a group not participating in the program). A random effects regression model controlling for retrospective risk, age, sex, and diagnosis with a chronic disease was used to determine the impact of program participation on market-adjusted health care expenditures. Further confirmation of results was obtained by an ordinary least squares model comparing market- and risk-adjusted costs to the length of participation in the program. Participation in the program is associated with an average annual savings of $\$ 1157.91$ per enrolled member in health care expenditures. Savings increase with the length of participation in the program. The results support the use of telephone-based patient self-management of chronic disease as a cost-effective means to reduce health care expenditures in the working-age population. (Population Health Management 2016;19:156-162)
\end{abstract}

\section{Introduction}

C HRONIC DISEASE IMPOSES significant challenges for the US health system. It is estimated that almost half of Americans experience a chronic disease, 1 in 4 suffers from multiple chronic conditions, and the costs of chronic disease, estimated using data from the 2006 Medical Expenditure Panel Survey, account for nearly $84 \%$ of US health care expenditures. ${ }^{1}$ Managing such conditions in order to minimize the cost and maximize patient quality of life is therefore a critical issue in health care. Because care for such diseases is a day-to-day, ongoing process that essentially consists of lifestyle changes, much of this management necessarily consists of selfmanagement, with patients as their own primary care provider and traditional care providers functioning as consultants, rather than directors and active participants, in managing the disease. ${ }^{2}$

Numerous programs have been created by health care providers, health agencies, and the payer community to try to educate and support patients in effective self-management of their condition. ${ }^{3}$ In contrast to traditional patient education, such efforts focus less on technical skills and diseasespecific information and more on problem solving and social coping mechanisms in order to develop greater self-efficacy in the area of care management. ${ }^{2,4-6}$ This approach has been found to be more effective in producing behavior change and improved disease control than the traditional approach. ${ }^{7,8}$ Techniques such as coaching and motivational interviewing are a known body of work.

Increased patient activation and engagement has been associated with improved outcomes and reduced costs. ${ }^{10}$ The question remains open, however, as to whether such a program can actually reduce the economic burden of increased health care expenditures for patients with a chronic condition. The evidence base is somewhat limited as few studies of disease management programs have looked at the impact on health care expenditures. ${ }^{11}$ Of studies that do, few effectively describe program elements well enough to determine which elements have an impact on cost. ${ }^{12} \mathrm{Al}-$ though it is often assumed that preventive services reduce net health care expenditures, that assumption is not always valid. ${ }^{13}$ In general, studies that have looked at the impact of disease management programs on costs have found evidence that the programs reduce health care utilization, but not necessarily costs. For example, Fireman et al, studying a provider-based program operated by the Permanente Medical Group of Northern California, found that the program

\footnotetext{
${ }^{1}$ American Health Data Institute, Indianapolis, Indiana.

(C) The Author(s) 2015; Published by Mary Ann Liebert, Inc. This Open Access article is distributed under the terms of the Creative Commons Attribution Noncommercial License (http://creativecommons.org/licenses/by-nc/4.0/) which permits any noncommercial use, distribution, and reproduction in any medium, provided the original author(s) and the source are credited.
} 
increased the use of underutilized care and improved physiological indicators of health, but did not result in overall savings because of the high cost of the disease management program, which included not just coaching components but significant efforts to change primary care delivery. ${ }^{14}$

In contrast, others have found that such programs can reduce health care utilization. Lorig et al estimated annual savings in 2001 of between $\$ 320$ and $\$ 590$ for a peer-led group self-management program operated by Stanford University. ${ }^{15}$ A similar study of a peer-led group diabetes management program operated by the University of Michigan found savings in hospital costs, but did not look at the broader impact on medical expenditures. ${ }^{16}$ Likewise, Hibbard et al found that a program assessing patient self-management skills and tailoring coaching support to those skills reduced hospital and emergency room (ER) utilization, but with no assessment of overall savings, in a program operated by LifeMasters (LifeMasters Supported SelfCare, Irvine, CA) that focused on members with diabetes, chronic obstructive pulmonary disease, congestive heart failure, asthma, and coronary artery disease. ${ }^{17}$ Villagra and Ahmed, evaluating a diabetes management program involving phone and Internet support coupled with remote monitoring, found health care expenditures reductions of \$137/ month. ${ }^{18}$ Little data, aside from that provided by the Hibbard and Villagra studies, exist on the impact of telephone-based self-management programs on health care expenditures. The current study proposes to increase the evidence base regarding the economic effect of telephone-based self-management programs by examining data on one such program.

\section{Methods}

\section{Program description}

The American Health Data Institute (AHDI) created its chronic disease management program, the Healthcare Navigator, in 2002. The objective of the Healthcare Navigator program is to help client companies reduce their health care costs by improving both self-care and the receipt of appropriate preventive care from formal health care providers, and is a part of an integrated approach to managing health care utilization. ${ }^{19-21}$ The program is insurer based and is offered as a contract component primarily to self-insured employers through their third-party administrator, but also through some co-op plans created as a result of the Patient Protection and Affordable Care Act. The program uses medical claims to identify individuals who are at risk because of a chronic condition, provides access to a Healthcare Navigator nurse for education and guidance for these patients, and identifies the subset of those individuals who have not met guidelinebased minimum health care standards for their conditions.

The program initially used nurses to provide technical information on the patient's chronic condition and to educate patients on guideline-based minimum health care requirements through written and phone contact. This training is considered crucial to ensure that case managers have appropriate psychosocial skills to support behavioral change in patients. ${ }^{22}$ Early in the program's development, AHDI implemented an internally developed computer application to assist with this effort. A significant change in focus to support behavioral change through motivational interviewing occurred in 2008. Currently, each member of the nursing staff receives training in motivational interviewing before beginning to work with participating program members, with periodic ongoing training conducted to further develop their skills.

Identification of patients with a chronic illness is the first step in the process. This is accomplished by either reviewing claims data or the health risk assessments completed by the patient to identify members who have 1 or more of 24 conditions addressed by the program (Table 1). Patients identified as having a chronic condition are then reviewed, primarily using claims information to determine if there is documentation to support that at least the minimal guidelinerecommended care to monitor the condition has been received. These are intended as a floor rather than a ceiling on tertiary preventative care. Individuals who are identified to have 1 or more chronic illnesses are targeted to receive communication regarding suggested care for their illness. For individuals identified as not receiving minimal care, follow-up reminders to the patient are undertaken.

In terms of coaching and education, the program begins by discussing with members what they know about their diagnoses and the needed follow-up and treatment. The nurse then coaches patients using a collaborative approach to encourage them to think about and work on lifestyle choices to improve their health with the intent of helping the patients prevent or minimize complications from their chronic illnesses. Nurses explore members' acceptance of the diagnosis, values related to health, their perceived self-efficacy, and perceived barriers to managing self-care and the disease. The interviews are used to help members identify ways to manage their condition and improve their ability to do so. These efforts are intended to not only reduce or prevent future out-of-pocket expenses

Table 1. Chronic Diseases Used for Identification of Health Care Navigator Participants

1. Asthma
3. Atherosclerosis
5. Atrial Fibrillation
7. Chronic Obstructive Pulmonary Disease (COPD)
9. Chronic Renal Insufficiency
11. Congestive Heart Failure
13. Coronary Artery Disease
15. Diabetes
17. Epilepsy
19. Hyperlipidemia
21. Hypertension (HTN)
23. Hyperthyroidism

IBD, inflammatory bowel disease
2. Hypothyroidism
4. Metabolic Syndrome
6. Multiple Sclerosis
8. Parkinson's Disease
10. Polymyalgia rheumatic
12. Prediabetes
14. Pulmonary HTN/Cor Pulmonale with or without COPD
16. Rheumatoid Arthritis
18. Regional Enteritis (IBD)
20. Sleep Apnea
22. Thromboembolic Disease
24. Ulcerative Colitis 
related to health care costs from added medications and inpatient hospital stays, but also to improve the quality of life for those who may need the greatest helping hand.

\section{Data}

Data were collected on 126,245 members from databases maintained by AHDI of claim and disease management information generated from members of health plans managed by Key Benefit Administrators and other client thirdparty health plan administrators. Eligible subjects had to have continuous enrollment in health plans from January 1, 2013, through November 30, 2014. Data on age and sex were collected from member information tables. Member zip codes were used to assign members to a Dartmouth Atlas Hospital Referral Region (HRR) using the 2012 zip code crosswalk (http://www.dartmouthatlas.org/downloads/ geography/ZipHsaHrr12.xls), with 2 indicator regions for unmatched zip codes in the United States and postal codes in Canada. Members were located in 297 HRRs plus the 2 indicator groups.

Within the larger data set, members of health plans with a subscription to the chronic disease management program were identified as having a potential chronic disease if they had been identified through program screening software as having a claim at any time prior to the start of the analytical period with an International Classification of Diseases, Ninth Revision, Clinical Modification (ICD-9-CM) diagnosis code indicating a program-relevant chronic condition that was subsequently verified by program staff. In groups without a subscription, members were identified as having a potential chronic condition if they had a claim at any time prior to the start of the analytical period with an ICD-9-CM diagnosis code indicating a program-relevant chronic condition. Each member's disease status was represented by an indicator for having been identified under program criteria as having a chronic disease and a second indicator variable for having a chronic disease and enrollment in a group subscribing to the program. For the purposes of this study, the program criteria for identifying members is used to assemble the data set for subjects enrolled in both subscribing and non-subscribing health plans, which eliminates a potential confounding issue in the analysis by ensuring consistency between the participant and nonparticipant reference set in the definition of members with a chronic condition. Studies using nonparticipants as a control group risk effects from confounding if participation is voluntary, as subject motivation can be related to both participation and self-management of the disease. Because enrollment in the program is a decision of the health plan, not the member, and the participation variable is based on intent to treat as evidenced by enrollment rather than an individual subject's decision to participate, the participation variable decouples participant motivation from assignment to the treatment or comparison group. This eliminates this particular problem. ${ }^{27}$

Allowed charges were aggregated by member for services used between January 1, 2013, and December 31, 2013. Allowed charges did not include pharmacy claims, as those data were not available for all third-party plans enrolled in the chronic disease management program. For each Dartmouth HRR, a price index was calculated by dividing the average allowed charges for members in the market without a chronic condition by the overall average for members without a chronic condition. Allowed charges were adjusted for market price differences by dividing each member's allowed charges by the index. Table 2 displays the adjustments for the 15 HRRs with the most subjects.

The Retrospective Episode Risk Grouping (RERG) value was generated by the Ingenix Symmetry Episode Risk Groups 7.5 software (Optum, Inc., Eden Prairie, MN) using claims for the time period of November 1, 2013, through October 31, 2014. The RERG is generated by grouping claims into treatment groups, which are aggregated into risk groups of similar clinical and risk characteristics. A risk score is calculated using predetermined weights for the member's profile of risk groups. Because member age and sex are not included in the RERG, they are included as separate covariates for risk adjustment in the econometric model.

This study was internally reviewed and determined to be exempt under the common rule as it involved the "collection of existing data... if the information is recorded by the investigator in such a manner that subjects cannot be identified." 23 A description of the sample can be found in Table 3.

\section{Econometric analysis}

Cost savings were estimated by a random effects regression model using the general net economic benefits framework described by Hock et al. ${ }^{24}$ To get an efficient estimation of treatment effects, a random effects least squares model was used based on the assumption that the variation in individual expenditures within markets was uncorrelated with other predictor variables. The estimation model took the basic form of:

$$
\text { Expenditures }=\mathrm{B}_{0}+\Sigma \mathrm{B}_{\mathrm{n}} \mathrm{X}_{\mathrm{n}}+\delta \mathrm{T}+\mathrm{U}_{\mathrm{i}}+\mathrm{W}_{\mathrm{ij}}
$$

Where $X_{n}$ represents the matrix of subject sex, age, existence of a chronic disease in a subject, and retrospective episode risk, $U_{i}$ the error term related to market-level (Dartmouth Atlas HRR) effects, and $\mathrm{W}_{\mathrm{ij}}$ the error of the individual member within the market. $\mathrm{T}$ is an indicator

Table 2. Adjustments to Allowed Charges FOR THE TOP 15 Study RefERRAL REgions

\begin{tabular}{lccc}
$\begin{array}{l}\text { Dartmouth Health } \\
\text { Referral Region }\end{array}$ & \#Members & $\begin{array}{l}\text { Average } \\
\text { Allowed }\end{array}$ & $\begin{array}{l}\text { Average } \\
\text { Adjusted } \\
\text { Allowed }\end{array}$ \\
\hline Seattle & 12862 & $\$ 5344.17$ & $\$ 4953.44$ \\
Eugene & 8407 & $\$ 4957.18$ & $\$ 4346.15$ \\
Portland & 7966 & $\$ 5289.09$ & $\$ 5665.23$ \\
Colorado Springs & 6216 & $\$ 6906.23$ & $\$ 12,576.83$ \\
Everett & 6030 & $\$ 6130.06$ & $\$ 4963.63$ \\
Hartford & 5470 & $\$ 6952.42$ & $\$ 8463.66$ \\
Johnstown & 5173 & $\$ 7905.09$ & $\$ 10,243.67$ \\
New Haven & 3879 & $\$ 7585.19$ & $\$ 9072.21$ \\
Yakima & 3795 & $\$ 5482.56$ & $\$ 5044.41$ \\
Boston & 3730 & $\$ 8268.01$ & $\$ 6793.43$ \\
Muncie & 3722 & $\$ 8258.37$ & $\$ 7199.19$ \\
Indianapolis & 2823 & $\$ 8174.94$ & $\$ 9506.82$ \\
Providence & 2120 & $\$ 6015.92$ & $\$ 6297.85$ \\
Tacoma & 2098 & $\$ 5981.11$ & $\$ 6298.44$ \\
Albuquerque & 1979 & $\$ 6998.64$ & $\$ 8078.61$ \\
\hline
\end{tabular}


TABle 3. Sample Description

\begin{tabular}{|c|c|c|c|}
\hline Variable & $\begin{array}{l}\text { Chronic Disease in a } \\
\text { Participating Group }\end{array}$ & $\begin{array}{l}\text { Chronic Disease in a } \\
\text { Nonparticipating Group }\end{array}$ & No Chronic Disease \\
\hline $\mathrm{N}=$ & 16,224 & 13,509 & \\
\hline Mean Age in Years (SD) & $48.6(15.1)$ & $47.2(14.2)$ & $41.0(17.7)$ \\
\hline Male & $48.1 \%$ & $52.1 \%$ & $47.6 \%$ \\
\hline Allowed Charges (SD) & $\$ 8400.11(\$ 22,488.53)$ & $\$ 9955.826(\$ 33,786.88)$ & $\$ 5453.39(\$ 21,979.24)$ \\
\hline RERG Value (SD) & $2.149(2.861)$ & $1.848(3.926)$ & $1.231(2.574)$ \\
\hline \multicolumn{4}{|l|}{ Number of Conditions } \\
\hline 1 & $4607(28.4 \%)$ & $6200(45.9 \%)$ & N/A \\
\hline 2 & $4137(25.5 \%)$ & $3037(22.9 \%)$ & N/A \\
\hline 3 & $3484(21.5 \%)$ & $1916(14.2 \%)$ & N/A \\
\hline 4 & $2063(12.7 \%)$ & $1135(8.4 \%)$ & N/A \\
\hline 5 & $1114(6.9 \%$ & $592(4.4 \%)$ & N/A \\
\hline 6 & $463(2.9 \%)$ & $322(2.4 \%)$ & N/A \\
\hline 7 or more & $195(2.2 \%)$ & $138(2.3 \%)$ & N/A \\
\hline Mean Number (SD) & $2.63(1.56)$ & $2.22(1.61)$ & N/A \\
\hline \multicolumn{4}{|l|}{ Conditions } \\
\hline Asthma & $3911(21.4 \%)$ & $2019(14.9 \%)$ & N/A \\
\hline Atherosclerosis & $244(1.5 \%)$ & $270(2.0 \%)$ & N/A \\
\hline Atrial Fibrillation & $484(3.0 \%)$ & $306(2.3 \%)$ & N/A \\
\hline COPD & $1308(8.1 \%)$ & $957(7.1 \%)$ & N/A \\
\hline Chronic Renal Insufficiency & $258(1.6 \%)$ & $151(1.1 \%)$ & N/A \\
\hline Congestive Heart Failure & $351(2.2 \%)$ & $259(1.9 \%)$ & N/A \\
\hline Coronary Artery Disease & $1625(10.0 \%)$ & $1418(10.5 \%)$ & N/A \\
\hline Depression & $2913(18.0 \%)$ & $3472(27.7 \%)$ & N/A \\
\hline Diabetes Mellitus & $3424(21.1 \%)$ & $2010(14.9 \%)$ & N/A \\
\hline Epilepsy & $307(1.9 \%)$ & $155(1.1 \%)$ & N/A \\
\hline HIV Infection & $33(0.2 \%)$ & $30(0.2 \%)$ & N/A \\
\hline Hyperlipidemia & $10212(62.3 \%)$ & $6571(48.6 \%)$ & N/A \\
\hline Hypertension & $9335(57.5 \%)$ & $5678(42.0 \%)$ & N/A \\
\hline Hyperthyroidism & $469(2.9 \%)$ & $319(2.4 \%)$ & N/A \\
\hline Hypothyroidism & $2600(16.0 \%)$ & $2026(15.0 \%)$ & N/A \\
\hline Metabolic Disorder & $519(3.2 \%)$ & $319(2.4 \%)$ & N/A \\
\hline Multiple Sclerosis & $117(0.7 \%)$ & $107(0.8 \%)$ & N/A \\
\hline Parkinson's Disease & $24(0.1 \%)$ & $15(0.1 \%)$ & N/A \\
\hline Polymyalgia Rheumatica & $56(0.3 \%)$ & $73(0.5 \%)$ & N/A \\
\hline Prediabetes & $1772(10.9 \%)$ & $1535(11.4 \%)$ & N/A \\
\hline Pulmonary Hypertension & $135(0.9 \%)$ & $102(0.8 \%)$ & N/A \\
\hline Rheumatoid Arthritis & $339(2.1 \%)$ & $259(1.9 \%)$ & N/A \\
\hline Schizophrenia & $34(0.2 \%)$ & $57(0.4 \%)$ & N/A \\
\hline Sleep Apnea & $1892(11.7 \%)$ & $1263(9.3 \%)$ & N/A \\
\hline Thromboembolic disease & $232(1.4 \%)$ & $201(1.5 \%)$ & N/A \\
\hline Ulcerative Colitis & $198(1.2 \%)$ & $113(0.8 \%)$ & N/A \\
\hline
\end{tabular}

COPD, chronic obstructive pulmonary disease; RERG, Retrospective Episode Risk Grouping; SD, standard deviation

variable for participation in the chronic disease management program and the coefficient $\delta$ thus represents the magnitude of change in health care expenditures that results from program participation. Model estimation was conducted using Stata/SE 10.0 for Windows 64bit x86-64 (StataCorp LP, College Station, TX).

The analysis was conducted on an intent-to-treat basis, with all members identified with a chronic disease in a member group that subscribed to the disease management program considered to be enrolled in the program, regardless of continuing participation. It has been suggested that evaluations of disease management programs are sensitive to selection bias because of preferential enrollment of subjects who have greater motivation..$^{25-27}$ By using health plan, rather than member, enrollment in an intent-to-treat model, this study decouples the role of motivation in defining participant and nonparticipant subjects.

After estimation, expected values of health care expenditures were calculated for members enrolled in the program under both the assumptions of participation $(\mathrm{T}=1)$ and nonparticipation $(\mathrm{T}=0)$. These values were used to calculate the average expected difference in charges after risk adjustment.

Finally, the impact of length of participation in the program is calculated by looking at the deviations from expected costs versus time. A base value for calculating risk-adjusted expected expenditures was calculated by totaling the values of market-adjusted expenditures and dividing by the total RERG values for all members. This was then multiplied by the individual RERG to create a risk- and market-adjusted estimate of the expected health care expenditure for the member. The 
focusing on self-management as well as those observed for programs delivered in the small group setting, ${ }^{15,17}$ providing further confirmation that coaching chronic disease patients on self-management can be an effective tool for controlling health care expenditures.

Although not examining pharmaceutical expenditures, these results are more robust in examining the overall impact of the disease management program on medical expenditures than previous studies. In their studies Hibbard and Lorig focused on the count of hospitalizations, ER, and physician visits as outcome measures and estimate cost impact from those counts. ${ }^{15,16}$ Wheeler's study considered only hospital and ER utilization. ${ }^{17}$ In contrast, the current study takes a broader approach to evaluating the impact on expenditures. Fireman's study also takes a broad approach and also finds a significant reduction in health care expenditures relative to control populations, but examines a more comprehensive and costly program in which the effects of the coaching component are not separated from those of provider practice interventions. ${ }^{14}$ By looking only at a coaching intervention, the current study provides evidence of the potential cost savings of a purely patient-oriented disease management coaching approach. Beyond those factors, the evidence that duration of participation in the program is related to savings, although weak, is not present in any of the aforementioned studies, but does show a relationship between the magnitude of exposure to the program and the level of savings, which increases the strength of evidence confirming that disease management programs do reduce the level of health care expenditures in the population of members with chronic diseases.

The finding that a telephone-delivered program results in a reduction in expenditures is significant because such a program, unlike one that relies on face-to-face participation in a small group setting, has lower transaction costs to the patient. The patient receives the coaching services in the home, and contacts can be tailored to his or her schedule. Although a comparison of actual uptake rates of participation between in-person and telephone-delivered programs is beyond the scope of this study, the findings of a significant reduction in health care expenditures for a telephone-delivered program suggests the potential for at least the same, if not greater, impact on population-level expenditures from the use of the telephone-based delivery mechanism.

It should be noted that the savings observed are average savings per member of a group participating in the disease management program, not just members with the chronic condition. This does not appear to be a selection effect arising from differentials in risk between participating and nonparticipating groups, as the models adjust for risk and, as seen in the description of the data, the average member in participating groups is at a slightly higher risk for higher expenditures than counterparts in nonparticipating groups. Because the intervention targets members identified by program criteria as having a chronic disease, and evidence on the trend of the length of time for individual participation versus health care expenditures provides some confirming evidence that participation lowers cost, the evaluation supports a belief that the management program has a positive impact on lowering health care expenditures for the targeted population with chronic diseases.
Given the large effect that chronic disease has on health care utilization and expenditures, the growing evidence that these programs can reduce the level of utilization for patients with chronic diseases suggests that efforts to improve self-management can have a significant impact on global health care expenditures if delivered efficiently. The present work suggests that a telephone-based coaching effort is one such mechanism that can be effectively integrated into a benefits package to help control health care costs.

\section{Author Disclosure Statement}

Drs. Avery and Cook, and Ms. Talens declared the following potential conflicts of interest with respect to the research, authorship, and/or publication of this article: All authors are employees of the American Health Data Institute (AHDI), which operates the evaluated program. This study was performed as an internal program evaluation by AHDI staff. The authors received no other financial support for the research, authorship, and/or publication of this article.

\section{References}

1. Robert Wood Johnston Foundation. Chronic Care: Making the Case for Ongoing Care. Princeton, NJ: The Robert Wood Johnson Foundation; 2010.

2. Bodenheimer T, Lorig K, Holman H, Grumbach K. Patient self-management of chronic disease in primary care. JAMA. 2002;288:2469-2475.

3. Barlow J, Wright C, Sheasby J, Turner A, Hainsworth J. Self-management approaches for people with chronic conditions: a review. Patient Educ Couns. 2002;48:177-187.

4. Marks R, Allegrante JP. A review and synthesis of research evidence for self-efficacy-enhancing interventions for reducing chronic disability: implications for health education practice (part II). Health Promot Pract. 2005;6:148-156.

5. Hill-Briggs F. Problem solving in diabetes self-management: a model of chronic illness self-management behavior. Ann Behav Med. 2003;25:182-193.

6. Linden A, Butterworth S, Prochaska JO. Motivational interviewing-based health coaching as a chronic care intervention. J Eval Clin Pract. 2010;16:166-174.

7. Wagner EH, Austin BT, Davis C, Hindmarsh M, Schaefer J, Bonomi A. Improving chronic illness care: translating evidence into action. Health Aff (Millwood). 2001;20(6): 64-78.

8. Clark N. Management of chronic disease by practitioners and patients: are we teaching the wrong things? BMJ. 2000;320:572-575.

9. Martins RK, McNeil DW. Review of motivational interviewing in promoting health behaviors. Clin Psychol Rev. 2009;29:283-293.

10. Greene J, Hibbard JH, Sacks R, Overton V, Parotta CD. When patient activation levels change, health outcomes and costs change, too. Health Aff (Millwood). 2015;34:431437.

11. Norris SL, Engelgau MM, Venkat Narayan KM. Effectiveness of self-management training in type 2 diabetes: a systematic review of randomized controlled trials. Diabetes Care. 2001;24:561-587.

12. Chodosh J, Morton SC, Mojica W, et al. Meta-analysis: chronic disease self-management programs for older adults. Ann Int Med. 2005;143:427-438.

13. Avery GH, Leonard KE, McKenzie SP. Economic implications of preventive care. In: Yih Y, ed. Handbook of 
Healthcare Delivery Systems. Boca Raton, FL: CRC Press; 2010:28-1-28-15.

14. Fireman B, Bartlett J, Selby J. Can disease management reduce health care costs by improving quality? Health Aff (Millwood). 2004;23(6):63-75.

15. Lorig KR, Ritter P, Stewart AL, et al. Chronic disease selfmanagement program: 2-year health status and health care utilization outcomes. Med Care. 2001;39:1217-1223.

16. Wheeler JRC. Can a disease self-management program reduce health care costs? The case of older women with heart disease. Med Care. 2003;41:706-715.

17. Hibbard J, Greene J, Tusler M. Improving the outcomes of disease management by tailoring care to the patient's level of activation. Am J Manag Care. 2009;15:353-360.

18. Villagra VG, Ahmed T. Effectiveness of a disease management program for patients with diabetes. Health Aff (Millwood). 2004;24(4):255-266.

19. Dust LR, Cook DB, inventors; Dust LR, Cook DB, assignees. Method of Optimizing Healthcare Consumption. United States patent 7,711,577. May 4, 2010.

20. Dust LR, Cook DB, inventors; Key Benefit Administrators, assignee. Method of Optimizing Healthcare Services Consumption. United States patent 8,036,916. October 11, 2011.

21. Dust LR, Cook DB, inventors; Key Benefit Administrators, assignee. Method of Optimizing Healthcare Services Consumption. United States patent 8,489,420. July 16, 2013.

22. Borbeau J, van der Palen J. Promoting effective selfmanagement programmes to improve COPD. Eur Respiratory J. 2009;33:461-463.

23. US Department of Health and Human Services. Protection of Human Subjects: Categories of Research That May Be
Reviewed by the Institutional Review Board Through an Expedited Review Procedure. Fed Regist. 2007;72:6084860851. Codified at 45 CFR $\S 46.101(b)(4)$.

24. Hoch JS, Briggs AH, Willan AR. Something old, something new, something borrowed, something blue: a framework for the marriage of health econometrics and cost-effectiveness analysis. Health Econ. 2002;11:415-430.

25. Luck J, Parkerton P, Hagigi F. What is the business case for improving care for patients with complex conditions? J Gen Intern Med. 2007;22(3 suppl):396-402.

26. Lewis A, Rearick D. Population Health Improvement Outcome Measurement: Buyer Beware! Waltham, MA: Disease Management Purchasing Consortium; 2011.

27. Buntin MB, Jain AK, Mattke S, Lurie N. Who gets disease management? J Gen Intern Med. 2009;24:649-55.

Address correspondence to: Dr. George Avery

Health Services Researcher, American Health Data Institute 8330 Allison Pointe Trail Indianapolis, IN 46250

E-mail: George.avery@ahdi.com

Dr. David Cook

Chief Medical Officer, The Key Family of Companies 8330 Allison Pointe Trail Indianapolis, IN 46250

E-mail: dcook@keybenefit.com 